\title{
Psychiatric Problems and Cultural Transitions in Alaska
}

\author{
JOSEPH D. BLOOM ${ }^{1}$
}

\begin{abstract}
Demographic characteristics of 105 Alaska Native patients referred for psychiatric evaluation are reviewed. Reasons for the referral are discussed and the psychiatric findings according to the DSM-II classification of the American Psychiatric Association are summarized. Particular attention is paid to the sociocultural environments from which the patients came. The patient population is dominated by women whose "career" seems to be distinctly different from that of the men in the sample. The pertinent psychological and anthropological literature is presented to give current conceptual models for understanding psychiatric problems in the cross-cultural framework.
\end{abstract}

RÉSUMÉ. Problèmes psychiatriques et transitions culturelles en Alaska. L'auteur passe en revue les caractéristiques démographiques de 105 patients indigènes de l'Alaska soumis à un examen psychiatrique. Il discute des raisons de l'examen et résume les résultats selon la classification DSM-II de l'American Psychiatric Association. Il porte un intérêt particulier au milieu socio-culturel d'origine de chaque patient. Le groupe de patients est dominé par les femmes dont la "carrière" semble très différente de celle des hommes de l'échantillon. L'auteur présente enfin les références psychologiques et anthropologiques pertinentes, afin de donner les modèles conceptuels courants pour comprendre les problèmes psychiatriques dans un cadre inter-culturel.

РЕЗЮМЕ. Психиатрические проблемы и кулътурные изменения на Аляске. Приводится обзор демографических характеристик 105 коренных жителей Аляски, направленных на психиатрические исследования. Обсуждаются причины осмотра больных, и заключения психиатрических исследований классифицируются соответственно требованиям Американской Психиатрической Ассоциации (классификация DSM-11). Особое внимание обращается на социально-культурную среду, из которой вышли әти больные. Среди исследованных жителей преобладали женщины, социальное семейное положение которых значительным образом отличалось от положения мужчин в исследованной группе. На основании соответствующей литературы по психологии и антрополотия приводятся современные идейные представления для понимания психиатрических проблем в условиях смешения культур.

\section{INTRODUCTION}

Alaska's history of cross-cultural contact presents a picture of intense activity alternating with periods of lull. The activity involved plundering attacks on the natural resources of the north whether they were animals of land or sea, or all-out assaults on the mineral wealth of the state, as with gold and now, potentially with petroleum. These periods of activity were accompanied by waves of population influx into the State, exemplified in early times by the Russian fur trader; later the miner, fisherman, and at present representatives of every major oil firm in the world. In some ways the people who have come to the north country have represented extremes of those who live in the more temperate climates. One extreme was the exploiter, who was out to make a fortune at any cost and who generally brought

ILangdon Psychiatric Clinic, Anchorage, Alaska, U.S.A. 
with him most of the so-called vices of civilized society. Following closely was the missionary, who also brought with him a special brand of reality. It is against this background of one hundred years of flux that one must look at the native peoples of the State of Alaska.

The waves of increased cross-cultural contact over the last one hundred years have been further accelerated since World War II, and have of necessity brought about major changes in the different native peoples. Today, of the approximately 53,000 people, 70 per cent live in 178 villages or towns that are predominantly native, and 30 per cent of the people live in the larger urban centres like Anchorage and Fairbanks (Federal Field Committee 1968). Although most of the people still live in the smaller villages with populations ranging from 50 to 700 people there are increasing numbers who are moving to the larger villages in rural Alaska, such as Bethel, Barrow, Nome, Kotzebue and Dillingham. (Federal Field Committee 1968). These larger rural towns are generally regional centres of communication and of governmental services.

For example, Bethel, a town of some 2,400 people, of which 77 per cent are Eskimo (Bureau of Indian Affairs 1971), is located in the southwestern part of the State. The town functions as the supply and communication centre for a huge triangular land mass bounded by the delta regions of the Yukon and Kuskokwim Rivers, and the Bering Sea. Bethel was founded in 1884 by missionaries of the Moravian Church. In addition to its being a communications centre, it houses the major medical institution of the region, the regional high school, the district judge's office, the regional offices of state and federal agencies like the Bureau of Indian Affairs, the State Department of Public Welfare, the Office of Economic Opportunity, the Alaska Department of Fish and Game, etc. Each agency serves the town of Bethel and the more isolated villages on an itinerant basis.

Up until the past two to three years, when native political groups began to develop power Bethel was basically a white man's town. It represented an intermediary point in the transition from the more traditional cultural pattern of the isolated villages to the cities. As a transitional community Bethel is a pocket of many psycho-social problems. Hippler (1969) offered similar viewpoints about the towns of Barrow and Kotzebue, as did Ervin (1969) for the town of Inuvik. This will be discussed in detail below.

\section{PSYCHIATRIC REFERRAL: THE SETTING}

The major effort of this paper is to review in quantitative descriptive terms some characteristics of 105 direct psychiatric referrals made to the author while on active duty as a psychiatrist with the Indian Health Service of the United States Public Health Service from 1966-68. In 1966 the Indian Health Service funded its first mental health unit in Alaska. This unit was made up of a psychiatrist, psychologist, and psychiatric social worker and was given the primary responsibility of developing mental health consultation for the rural hospitals situated in the northern and western part of the State. The 105 cases described are only those seen directly and do not include those patients discussed in indirect consultation. 
The Indian Health Service maintains 7 general hospitals within Alaska. There is a 300-bed medical centre and referral hospital in Anchorage, which serves the outlying areas of the State. There are 6 other general hospitals: a 160-bed hospital at Mount Edgecumbe in Southeast Alaska, a 65-bed hospital at Bethel, a 55-bed hospital at Kotzebue, 35-bed hospitals at Kanakanak and Tanana and a 12-bed hospital at Barrow. Each of these is run by general medical officers who were expected to handle a complete range of medical practice, including patients with acute and chronic psychiatric problems.

The Eskimo group makes up the majority of the sample studied as follows: 63 per cent of the sample were Eskimo, 15 per cent were Indian (mainly Athapascan), 12 per cent were Aleut and 10 per cent were of mixed origin. According to the 1970 Census (BIA 1971) the Eskimo-Aleut population accounts for 63 per cent of the total Native population of Alaska. In this paper the Eskimo-Aleut group accounts for 75 per cent of the patient sample. This figure of 75 per cent simply reflects the travel pattern of the unit, and does not reflect the mental health problems of any one ethnic group.

The sample is further defined by looking at who initiated referral for psychiatric consultation. Eighty-one per cent of the cases were referred by physicians within the general hospitals of the Indian Health Service. Only 13 per cent of the cases were referred by social workers from the various social agencies both in Anchorage and in the rural cities. Only a very few referrals came from ministers, courts, schools, etc. The sample has a definite medical-hospital bias and reflects the types of activities which make for referral within a medical care system. Stated simply, doctors will tend to refer those people who are puzzling (the concept of differential diagnosis), those causing trouble (various forms of acting out behaviour) and those with a history of mental illness in the past (the disease concept of mental illness). This brings up the question of who goes to hospitals as opposed to other catchment networks such as social agencies or the courts. This will be discussed below.

TABLE 1. Marital status by sex.

\begin{tabular}{lcccccc}
\hline & Married & Single & Divorced & Separated & Widowed & Total \\
\hline Male & 12 & 23 & 0 & 2 & 2 & 39 \\
Female & 19 & 37 & 4 & 4 & 2 & 66 \\
Total & $31(29 \%)$ & $60(57 \%)$ & $4(4 \%)$ & $6(6 \%)$ & $4(4 \%)$ & $105(100 \%)$ \\
\hline
\end{tabular}

TABLE 2. Birthplace and current residence

\begin{tabular}{lcc}
\hline & Birthplace & Current Residence \\
\hline Village & $70(67 \%)$ & $31(30 \%)$ \\
Rural Town & $19(18 \%)$ & $48(45 \%)$ \\
City & $4(4 \%)$ & $26(25 \%)$ \\
Not Ascertained & $12(11 \%)$ & 0 \\
\hline
\end{tabular}




\section{RESULTS}

The sample consists of 105 cases, 66 were female (63 per cent), and 39 were male ( 37 per cent). When compared with the general population breakdown by sex (Federal Field Committee 1968), the sample population was found to be significantly different (less than .01 level). The mean age of the men was 32 years and that of the women was 29 years. (The median case was aged 32 for men and 25 for women.) Marital status is presented by sex in Table 1. Only 31 per cent of the men and 29 per cent of the women were married. Furthermore, the sample population was made up more of people who were never married (57 per cent) than of those who were married and experienced divorce or separation. There was no statistically significant difference in marital status by sex. This appeared to be a generally unmarried group of people although comparison with the general population was not possible because of lack of data available on the general population.

An attempt was made to assess the mobility patterns of the population. This was done by comparing the birthplace of each patient with his current place of residence. Table 2 presents the data on birthplace and on the current place of residence. The migration pattern from village to rural town to urban centre is clearly illustrated. When this mobility pattern is broken down by sex the data suggest that women are moving to new places of residence more frequently than the men. This trend was found statistically significant at the .05 level. Table 3 compares the data presented in Table 2 by sex.

TABLE 3. Change of residence by sex.

\begin{tabular}{lccc}
\hline & Change & No Change & $\begin{array}{c}\text { No Information } \\
\text { Available }\end{array}$ \\
\hline Male & 13 & 21 & 5 \\
Female & 32 & 27 & 7 \\
Total & 45 & 48 & 12 \\
\hline
\end{tabular}

TABLE 4. Occupation by sex.

\begin{tabular}{lccc}
\hline & Male & Female & Total \\
\hline Traditional & 5 & 2 & $7(7 \%)$ \\
Cash Oriented - Employed & 9 & 10 & $19(18 \%)$ \\
Cash Oriented - Unemployed & 12 & 8 & $20(19 \%)$ \\
Student & 2 & 8 & $10(9 \%)$ \\
Housewife & 0 & 17 & $17(16 \%)$ \\
None & 8 & 20 & $28(27 \%)$ \\
Welfare or State Support & 3 & 0 & $3(3 \%)$ \\
Not Ascertained & 0 & 1 & $1(1 \%)$ \\
\hline
\end{tabular}


Occupational status was difficult to assess and required some unconventional categorizing. The occupational status by sex is presented in Table 4. Several of the categories need explanation. The "traditional" category includes those people who most of the time are actively following a subsistence hunting and fishing way of life. The "none" category refers to those people of either sex who do not appear to have any type of solid sex- and age-specific occupation, whether traditional or otherwise. They seem to somehow have missed out in the development of sexspecific occupations and float from one type of job to another. They may pursue some hunting and fishing activities but not on a full-time basis, they have held cash-oriented jobs but never developed any particular field and will float from one job to the next. They are also quite dependent on the whims of non-natives for their livelihood. For example excerpts of the following letter illustrate the point being made here.

On November 4th there is a 26 week course in clerk-typist here in Bethel. We will receive subsistence allowance every week. It is available so I'm taking it. As for the carpentry work or training, it never started because of the factory not complete yet. If they don't have it complete by November 1st, the state will withdraw the funds for that training and forget about the training they'll give. That is one reason why I chose the clerk-typist course. (Personal communication to the author).

For women the most common non-occupation is occasional baby-sitting. Women occupied this "no-occupation" group significantly more than did the men (.05 level).

The behaviour or reasons which resulted in referral seemed to fall naturally into 3 main groups. The first group of 15 patients included those who had a past history of mental disorder, who had been labelled "psychiatric patients." In some cases these patients may not have been either actively symptomatic or have represented any type of a social problem for years. The second group, made up of 41 patients, demonstrated symptoms of psychiatric disorder in their presentation to the physician and were referred because of these symptoms. The third and largest group consisted of 49 patients. These demonstrated psychiatric symptoms but were seen mainly because of threats of some type of destructive acting out including suicide attempts and threats of violence directed to others. Within this third group was a group of young women who presented with a constellation of disturbed behaviour which included sexual acting out, depression with suicide attempts, and threats, often associated with the use of alcohol. These 3 groups reflect, as previously mentioned, the medical orientation of the referral system.

The precipitating crisis which led to psychiatric referral is presented in Table 5.

TABLE 5. Nature of current crisis by sex.

\begin{tabular}{|c|c|c|c|}
\hline & Men & Women & Total \\
\hline $\begin{array}{l}\text { Crisis of Broken or Strained } \\
\text { Interpersonal Relationship }\end{array}$ & 10 & 23 & $33(32 \%)$ \\
\hline Crisis of Migration or Uprooting & 1 & 10 & $11(10 \%)$ \\
\hline $\begin{array}{l}\text { Other, including illegitimate } \\
\text { preg., job difficulties, etc. } \\
\text { No Current Crisis }\end{array}$ & $\begin{array}{l}10 \\
18\end{array}$ & $\begin{array}{l}15 \\
18\end{array}$ & $\begin{array}{l}25(24 \%) \\
36(34 \%)\end{array}$ \\
\hline
\end{tabular}


The group represented in the "no current crisis" includes those people who have been involved in rather continuous problems for many years, and those who were called to the hospital for evaluation because of previously known mental disorder, with or without current problems. Aside from this category the largest group consisted of those people who were presented with a crisis of broken or strained interpersonal relationship (33 people). Within this largest single group was the crisis of marital strain or separation; this included 22 people, 16 of whom were women.

TABLE 6. Diagnosis by sex: (DSM-II).

\begin{tabular}{|c|c|c|c|}
\hline Diagnostic Category & Men & Women & Total \\
\hline $\begin{array}{l}\text { I. Mental Retardation: } \\
\text { 311- Mild mental retardation } \\
\text { 312-Moderate mental retardation }\end{array}$ & & 1 & 1 \\
\hline $\begin{array}{l}\text { II. Organic Brain Syndromes: } \\
\text { 291-Alcoholic psychosis } \\
\text { 292--Psychosis associated with intracranial infection } \\
\text { 293-Psychosis associated with other cerebral condition } \\
\text { 309-Non-psychotic organic brain syndromes }\end{array}$ & $\begin{array}{l}1 \\
1 \\
1 \\
2\end{array}$ & 1 & $\begin{array}{l}2 \\
1 \\
1 \\
3(7)\end{array}$ \\
\hline $\begin{array}{ll}\text { III. Psychoses: } & \text { acute } \\
\text { 295-Schizophrenia } & \begin{array}{l}\text { chronic } \\
\text { by history }\end{array} \\
\text { 296-Major affective disorders } \\
\text { 297_-Paranoid states } \\
\text { 298-Other psychoses }\end{array}$ & $\begin{array}{l}3 \\
8 \\
3\end{array}$ & $\begin{array}{l}2 \\
5 \\
1 \\
1 \\
1 \\
2\end{array}$ & $\begin{array}{l}22 \\
1 \\
1 \\
3(27)\end{array}$ \\
\hline $\begin{array}{l}\text { IV. Neuroses: } \\
\text { 300-Neuroses } \\
\quad 300.14 \text { Hysterical neurosis-dissociative type } \\
\quad 300.4 \text { Depressive neurosis }\end{array}$ & 2 & $\begin{array}{r}2 \\
13\end{array}$ & $\stackrel{2}{15(17)}$ \\
\hline $\begin{array}{l}\text { V. Personality Disorders: } \\
\text { 301- Personality Disorders } \\
301.1 \text { Cyclothymic personality } \\
301.2 \text { Schizoid personality } \\
301.3 \text { Explosive personality } \\
301.4 \text { Obsessive compulsive personality } \\
301.5 \text { Hysterical personality } \\
301.7 \text { Antisocial personality } \\
301.81 \text { Passive-aggressive personality } \\
\text { 301.82 Inadequate personality } \\
\text { 303-Alcoholism } \\
\text { 304-Drug dependence }\end{array}$ & $\begin{array}{l}3 \\
1 \\
1 \\
1 \\
6 \\
1\end{array}$ & $\begin{array}{l}5 \\
1 \\
1 \\
2 \\
5\end{array}$ & $\begin{array}{r}1 \\
2 \\
3 \\
1 \\
5 \\
2 \\
1 \\
3 \\
11 \\
11(30)\end{array}$ \\
\hline $\begin{array}{l}\text { VI. Psychophysiologic Disorders: } \\
\text { 305-Psychophysiologic disorders }\end{array}$ & & 3 & $3(3)$ \\
\hline $\begin{array}{l}\text { VIII. Transient Situational Disturbance: } \\
\text { 307-Transient situational disturbance } \\
\text { 307.2 Adjustment reaction of adolescence } \\
\text { 307.3 Adjustment reaction of adult life }\end{array}$ & $\begin{array}{l}2 \\
1\end{array}$ & $\begin{array}{l}4 \\
2\end{array}$ & $\begin{array}{l}6 \\
3\end{array}(9)$ \\
\hline $\begin{array}{l}\text { IX. Behavior Disorders of Adolescence: } \\
\text { 308- Behavior disorders of Adolescence } \\
\text { 308.1 Withdrawing reaction of adolescence } \\
\text { 308.3 Runaway reaction of adolescence }\end{array}$ & & $\begin{array}{l}4 \\
2\end{array}$ & $\begin{array}{l}4 \\
2\end{array}(6)$ \\
\hline $\begin{array}{l}X . \text { Conditions Without Manifest Psychiatric Disorder: } \\
\text { 318-No mental disorder }\end{array}$ & 1 & & 1 \\
\hline $\begin{array}{l}\text { XI. Non-Diagnostic Terms for Administrative Use: } \\
\text { 319-Non-diagnostic terms for administrative use } \\
\text { 319.0 Diagnosis deferred }\end{array}$ & & 3 & $3(4)$ \\
\hline
\end{tabular}


TABLE 7. Summary — Diagnostic categories by sex.

\begin{tabular}{lccc}
\hline Diagnostic Category & Men & Women & Total \\
\hline I. Mental Retardation & 0 & 2 & $2(2 \%)$ \\
II. Organic Brain Syndromes & 5 & 2 & $7(7 \%)$ \\
III. Psychoses & 15 & 12 & $27(26 \%)$ \\
IV. Neuroses & 2 & 15 & $17(16 \%)$ \\
V. Personality Disorders & 13 & 17 & $30(28 \%)$ \\
VI. Psychophysiologic Disorders & 0 & 3 & $3(3 \%)$ \\
VIII. Transient Situational Disturbance & 3 & 6 & $9(8 \%)$ \\
IX. Behavior Disorders of Adolescence & 0 & 6 & $6(6 \%)$ \\
$X$. Conditions without Manifest Psychiatric Disorder & 1 & 0 & $1(1 \%)$ \\
XI. Non-Diagnostic Terms Diagnosis Deferred & 0 & 3 & $3(3 \%)$ \\
\hline
\end{tabular}

Finally, the diagnoses were translated into the new DSM-II classification (Committee on Nomenclature and Statistics 1968). Although this was done after the new classification came into being, and represents the work of only one person, it still represents an attempt to use the current standardized nomenclature for comparison with other workers. This is presented by sex in detail in Table 6 and summarized by sex in Table 7. Only first diagnoses are given. In this study diagnoses of alcohol consumption were given secondary status unless the use of alcohol was overwhelmingly prominent. Thus this diagnostic breakdown will reflect less alcohol usage than is commonly described in referring to psychiatric problems in Arctic communities.

Alcoholism per se did represent the largest single category diagnosed within the personality disorders with a definite male preponderance. When comparing overall diagnoses by sex the men were found to have significantly more psychosis and the women significantly more neurosis and personality disorders (both at the .03 level).

\section{DISCUSSION}

The patient population studied in this report is highly selected. It is composed of people in the general population who have been designated as mentally ill, or at least potentially mentally ill. Thus the subsequent discussion reflects on the total population only indirectly. It also should be kept in mind that two-thirds of the sample represents people living in either large rural towns or urban centres. The discussion thus applies more to these people than to village people. Most of the native people still live in villages but the numbers in rural towns and urban centres is growing.

The social and psychological environments of the large rural towns deserve comment. Hippler (1969) has written about the "Big Villages in Northwest Alaska," Barrow, Nome, and Kotzebue, and describes the growth of these villages as a result of the people's desire for better governmental services and opportunity 
for cash employment. He points out that the migrant to the big villages comes in contact with an "overall denigration of native culture and personality: resulting in towns with extremely unhealthy social environments." He postulates that these large villages incubate social and emotional problems for the larger cities.

Ervin (1969) described a similar situation in the northern Canadian town of Inuvik. He examined the conflicting styles of life which exist between the "Northerners" (the local Eskimos) and the "Southerners" (the agency people) with the resultant serious value disjunction which is occurring for Eskimos particularly in the age group 25 to 50 . He points out that the whole Arctic and Sub-arctic is facing an "incipient urbanization" with the coalescing of people into these concentrated communities built on southern models, in which Northern people experience minority group status and its attendant marginality.

Leighton (1959) in his discussion of community functioning as it relates to the prevalence of psychiatric disorder, has catalogued characteristics which point to sociocultural disintegration. These include: "high frequency of broken homes; few and weak associations (between people); few and weak leaders; few patterns of recreation; and a high frequency of hostility, crime and delinquency." The larger rural towns of Alaska demonstrate many of these features. There are also current signs of the reversal of this disintegrative spiral. The organization of local native corporations to deal with land claims, the adoption by state and federal agencies of native involvement in agency functioning all contain the seeds for the development of stronger communities.

In addition to where people live there are other aspects of the studied population which would indicate that this group is highly at risk for the development of mental disorder regardless of the type. Fried (1964), developed a causal matrix which tied together social problems and mental illness. Extremely important in this matrix is what Fried calls "crisis of transition," which includes economic depression, divorce and migration. He presents evidence that these factors are clearly related to first admissions to mental hospitals. Stated conversely, economic security, marriage, and stable living situation all militate against the development of subsequent psychopathology. These three factors are missing from the lives of a great many of the people studied. Fried makes the further point that any "single deprivation or disruption increases the likelihood that other deprivations and disruptions will occur." This snowballing effect, with crisis piled upon crisis, is characteristic of many of the cases seen, and will be described below in terms of the stresses of cultural contact and change. Regardless of the accuracy of the diagnostic categories this group represents a sample in which one would expect a high degree of psychopathology.

There are findings in this study which point to a different career for women. There were more women; they were younger, they seemed more prone to migration; they generally had less stable occupations; they were involved in more crises at presentation, especially crises of marital strain, and they presented a very different pattern on diagnostic assessment.

Does this apparent difference between what the sexes present indicate real differences in the stresses on men and women? Or does it represent a sampling error? There is some evidence to support both possibilities. 
As a sampling error it is entirely possible that the hospital casualty network tends to attract women more easily than men. Other casualty management networks like the judicial and correctional systems attract more men than women. For example, a study of the 1969 "Drunk-in-Public" Law in Alaska revealed that men were arrested for being drunk in public seven times more frequently than women. It might very well be postulated that the jails were managing the situational kinds of crises for the men, whereas the hospitals, and perhaps other social agencies were managing those for the women. This postulate would also help to explain some of the apparent differences between diagnostic categories of the men and women. The men with the more clearly psychiatric problems i.e., the psychoses come to the hospital, whereas those with neuroses, character disorders, and situational crises may be managed by the jails. The apparently high rates of alcohol consumption correlated with zealous activity by the police in relation to drunk-inpublic offences may automatically select the jail system as the main management area for the problems of the men.

There is also some evidence, from work done in Alaska to suggest that there are sex-related differences in psychological problems. Murphy (1960) in an epidemiological study of psychopathology in a northern Eskimo village, found that 26 per cent of the adult population had psychiatric symptoms, mostly of the psychoneurotic variety, and that twice as many women as men had these psychoneurotic symptoms. Chance $(1965,1966)$, in studies of the northern Eskimo communities of Barrow and Kaktovik, attempted to relate cultural change, identity and personality adjustment. He found that Kaktovik Village women tended to have higher emotional disturbance scores than the men. He postulated two main variables which related personality adjustment with cultural change: the extent of intercultural contact, and the degree that this contact has encouraged positive identification with western culture. He found that most women, and some of the men, had low scores on inter-cultural contact and high scores on western identification. He then related this finding to the major hypothesis of the paper, that women have less real contact with western culture than do men, yet may have a high identification with it. Thus they suffer an identity confusion often resulting in symptoms of emotional disturbance. Most of the epidemiological findings in Chance's studies $(1965,1966)$ related to a small village which he felt demonstrated positive cultural change. Whether these findings would hold in a rural city or an urban area is a question. In these places it seems that women have contact and identification with western culture but little chance of being truly accepted as full members of western society.

The above material suggests the need for further studies in specific areas. There is a clear need for studies of the different social environments designated in the shorthand of this paper as village, rural town and city. There is need for detailed investigations of the possible differential stresses which may fall upon men and women. The material further suggests a need for analysis of the case management networks for men and women. Finally there is a great need for studies of the family unit in the cross-cultural setting.

There has been little dovetailing between the growing literature on the family unit and cross-cultural research. Cross-cultural literature tends to view the in- 
dividual as he is molded within a cultural group and how this changes with culture change. The literature on the family seems to be influenced by sociologists who have tended to view the differences in family units by social class (Hill 1965) or by psychiatrists and psychologists who are interested in the inner workings of the family unit, the nature of family tasks and finally, the results of the family as a social system of its own producing psychological health or psychological dysfunction.

For example, in the problem presented earlier regarding different patterns of psychological morbidity by sex, family literature might be brought to the problem in the following manner. In the stable family there are differing role expectations for the sexes. Parsons and Bales (1955) consider the father's primary role to be "adaptive-instrumental" and the mother's, "integrative-expressive." Lidz (1957, 1967,1970 ) has translated the idea of role expectations and psycho-sexual identification within the family into a theory of personality development. He sees the family as serving a primary integrating and balancing function for the developing child. The ability to do this successfully is intimately tied to the parents' abilities to form a marital coalition, maintain the boundaries between themselves and their children and assist the child in developing a sexual identity which includes proper role differentiation. Bateson et al. (1969) have described the "double bind" as it applies to schizophrenia. This concept may have significant application in relation to the cognitive styles involved in cross-cultural conflict. Synthesizing the above material it is possible that cross-cultural stress is mediated by the family. The stress causes problems in the marital coalition and causes the child greater difficulty in developing the proper psycho-sexual identification and role structure. This is further heightened by the clash in cognitive styles between cultures. It may be possible that it is more difficult for a woman to master the "integrative-expressive" role than it is for the man to master the changing instrumentation necessary to support his role within the family.

Overall descriptions of life and problems in the Arctic have mainly been undertaken by anthropologists. Recent publications by Hughes (1960), Oswalt (1963a, b, 1967), and VanStone (1962) are primarily ethnological descriptions of various Eskimo groups, with special emphasis on the changing culture which has characterized the past 30 years. Boag (1966) has assembled a review article in which he cites the major material written in the English language regarding northern peoples. This includes descriptions of the so-called culture-bound syndromes and shamanism, as well as a review of the topic of cultural change.

There have been several descriptions of conditions which seem to be culturespecific to the arctic area. Leighton and Hughes (1955) describe patterns of Eskimo ritual suicide on St. Lawrence Island. Gussow (1963) describes a phobiclike syndrome, "Kayak-angst", as it appeared in West Greenland. Murphy and Leighton (1965) review the components of "Piblokto", a form of episodic excitement with a possible hysterical basis; and "Amurakh" which seemed to be confined to western Siberia and involved mainly a "copying mania." Teicher (1954) describes three cases of schizophrenia on Southampton Island in Northern Canada. He sees a common form of mental disorder, regardless of the culture, even though the content of the psychosis is related directly to the culture in which it occurs. 
Along with descriptions of culture-specific problems are discussions of the traditional curing mechanisms based on shamanism. Murphy (1964) describes the therapeutic aspects of shamanism on St. Lawrence Island and discusses the Eskimo conception of the causation of mental illness. These include loss of the soul, breach of a taboo, sorcery and intrusion into the body of either an object or a spirit.

In the cases described in this report there were elements of traditional content present in many of the cases. For example, one man who was diagnosed as schizophrenic experienced repeated episodes in which he said that his body was taken over by a white fox, during which time he would frighten his village. A man, not seen directly, was known to have committed suicide one month after he had been rescued from an ice floe, following which he was unable to bring himself to hunt. One man repeatedly asked his family to help him commit suicide in the old manner, because he was not a "good man." The family refused, tied him up, and had a plane sent to take him to the hospital. Several people described their souls leaving them; several were worried about "spirits". In no cases, however, were the traditional elements unified into one clinical presentation. Furthermore, although it is known that shamanism remains, it has been driven underground mainly by the established church-medical systems, and access to elements of traditional curing is no simple task to the outside observer. It is also interesting to note that elements of traditional content in these cases seemed limited to those people still living in the villages. They were not often present in the people living in rural cities or urban centres. The traditional content and description of syndromes seems to be fragmenting in the process of cultural change. They remain as vestiges of thought content and beliefs.

Berreman (1964) and Hughes (1957) have made use of reference group theory to provide an overall framework for cross-cultural analysis. Berreman, writing about the Aleuts of Nikolski, gives a detailed discussion of the concepts of reference group theory and how identification with "white" society has led to an alienation from the original Aleut group. He discusses this process as it eventually leads to problems of social mobility and finally to marginality. He defines the marginal person as that person who has "identified with a group into which he has not been accepted as a member." Brody $(1966,1968)$ described the "marginal man" as a person in a state of chronic disequilibrium belonging to neither his society of origin, nor to the dominant society. He uses the term "cultural exclusion", meaning an active process by which the out-group person fails to share in the experience and fails to be trained in the symbols of the dominant society. This person, thus, for the most part, is relegated to the fringes of the dominant society.

Both the Chance study (1966) and Parker's (1966) study of identity and acculturation make use of the reference group ideas in the design and analysis of the studies. Parker's work represents one of the few empirical studies which attempts to measure "acculturation" at two points on the continuum from village, to rural town, to urban centre. He did his work in Alakanuk, a lower Yukon River Eskimo village; and at Kotzebue, a large town on the Chukchi Sea. In each place his method was to present subjects with pictures which were designed to shed light on ethnic identity. The results show quite a different pattern of response in the village compared with the rural town. He found that the Kotzebue subjects ex- 
pressed more hostility, demonstrated a greater degree of both intra-ethnic and inter-ethnic social distance, and had a greater degree of attraction to the symbols of western society. He also compared the Eskimo adolescents' reaction to white adults, and found in both the village and the rural town that adolescents did not have a positive view of the white adults. In the village however, the attitude was relatively neutral, whereas in the town it was primarily negative. He sees the attitudes of the rural town's people, especially the adolescents, as carrying the potential for the development of serious social problems. This corresponds to the author's impressions of the attitudes and outlooks in the larger rural towns.

\section{CONCLUSION}

The entire northern region is now facing a crisis which Ervin (1969) called "incipient industrialization." This crisis in the cross-cultural setting has the potential to make the original Northerners marginal men on the fringe of the larger American society. This process has already taken firm hold in the North. On the positive side are some recent important political changes including the growth of the nativistic movements, the native land claims settlement between the natives of Alaska and the Congress of the United States, and the public recognition that the way oil development in Alaska is handled can greatly affect the quality of cultural change in the North. The key question of the next decade is whether political changes can be brought to bear on the lives of individual people in such a manner that will strengthen their internal psychological reserves and strengthen their internal sense of identity and of pride.

"Before the missionaries came, we lived underground in sod houses and laid away our dead on the tundra. ... Now we live above ground and bury our dead — and I haven't really been warm since."

Unidentified King Islander (Abercrombie 1969)

\section{REFERENCES}

ABERCRombie, T. J. 1969. Nomad in Alaska's outback. National Geographic 135(4): 540-67.

BaTESON, G. et al. 1969. Toward a theory of schizophrenia. In: Communication, Family and Marriage. Palo Alto: Science and Behavior Books. 278 pp.

BERREMAN, G. 1964. Aleut reference group alienation, mobility and acculturation. American Anthropologist, 66: 232-50.

BOAG, T. J. 1966. Mental health in the Arctic. Paper presented at the Fourth World Congress of Psychiatry, Madrid. 18 pp.

BUREAU of INDIAN AFFaIRS, 1971. Indian Population, 1970 Census - Census county divisions and places. Bureau of Indian Affairs Statistics Division Report. $11 \mathrm{pp}$.

BRODY, E. B. 1966. Cultural exclusion, character and illness. American Journal of Psychiatry, 122: $852-58$.

1968. Minority group status and behavioral disorganization. In: Brody and Silver, eds., Minority Group Adolescents in the U.S. New York: Basic Books. 256 pp.

CHANCE, N. 1965. Acculturation, self-identification, and personality adjustment. American Anthropologist, 67: 372-93. 
1966. The dynamics of change. In: The Eskimo of North Alaska, Case Studies in Cultural Anthropology. New York: Holt, Rinehart and Winston. pp. 80-100.

COMMITTEE ON NOMENClatuRe AND STATISTICS, 1968. Diagnostic and Statistical Manual of Mental Disorders, Washington, D.C.: American Psychiatric Association. 119 pp.

ERVIN, A. M. 1969. Conflicting style of life in a Northern Canadian town. Arctic. 22: 90-105.

FEDERAL FIELD COMMITTEE FOR DEVELOPMENT PLANNING IN ALASKa, 1968. Alaska Natives and the Land. Washington, D.C., U.S. Government Printing Office.

FRIED, M. 1964. Social problems and psychopathology. In: Urban America and the Planning of Health Services. New York: Group for the Advancement of Psychiatry. S-10.

Gussow, z. 1963. A preliminary report of kayak-angst among the Eskimo of West Greenland; a study in sensory deprivation. International Journal of Social Psychiatry, 9: 18-26.

HILL, R. 1965. Generic features of families under stress. In: Crisis Intervention: Selected Readings. New York: Family Service Association of America, pp. 32-52.

HIPPLER, A. E. 1969. The big villages in Northwest Alaska, a dimension in government research. Unpublished paper, University of Alaska.

HUGHES, c. c. 1957. Reference group concepts in the study of a changing Eskimo culture. Proceedings of the 1957 Annual Spring Meeting of the American Ethnological Society, pp. 7-14. pp. 387-88.

LEIGHTON, A. 1959. My Name Is Legion. New York: Basic Books. pp. 303-36.

LEIGHTON, A. and C. HUGHES. 1955. Notes on Eskimo patterns of suicide. Southwestern Journal of Anthropology, 2: 327-38.

LIDZ, T. 1967. The origins of schizophrenia: a new explanation. Mental Health Program Reports, National Institutes of Mental Health, PHS publication 1568, $801 \mathrm{pp}$.

1970. The family as the developmental setting. In: E. J. Anthony, M.D., C. Koupernik, M.D., eds. The Child in His Family. New York: Wiley-Interscience, 488 pp.

LIDZ, T. et al. 1957. The intrafamilial environment of schizophrenic patients; marital schism and marital skew. American Journal of Psychiatry, 114: 241-48.

MURPHY, J. 1960. An epiderniological study of psychopathology in an Eskimo village. Unpublished Ph.D. Thesis.

1964. Psychotherapeutic aspects of shamanism on St. Lawrence Island in Alaska. In: A. Kiev, ed. Magic, Faith and Healing, London: Free Press of Glencoe, pp. 53-84.

MURPHY, J. and A. LEIGHTON. 1965. Native conceptions of psychiatric disorder. In: Murphy and Leighton, eds. Approaches to Cross Cultural Psychiatry. Ithaca: Cornell University Press, pp. 64-107.

oswalt, w. 1963a. Napaskeak, An Alaskan Eskimo Community. Tucson: University of Arizona Press. 162 pp.

$170 \mathrm{pp}$.

$259 \mathrm{pp}$.

PARKER, s. 1966. Ethnic identity and acculturation in two Eskimo villages. American Anthropologist, 66: 325-39.

PARSONS, T. and R. BaLes. 1955. The Family. Glencoe. Free Press, 1945. 422 pp.

TEICHER, M. D. 1954. Three cures of psychoses among the Eskimos. Journal of Mental Science, 100: 527-35.

vanstone, J. 1962. Point Hope, An Eskimo Village in Transition. Seattle, University of Washington Press. 167 pp. 